\title{
MicroRNA-4500 suppresses tumor progression in non-small cell lung cancer by regulating STAT3
}

\author{
ZHI-YING LI $^{1 *}$, ZI-ZHOU ZHANG ${ }^{2 *}$, HUI BI ${ }^{1}$, QIU-DI ZHANG ${ }^{1}$, \\ SU-JUAN ZHANG ${ }^{1}$, LIN ZHOU ${ }^{1}$, XIAO-QIN ZHU ${ }^{1}$ and JUN ZHOU ${ }^{1}$ \\ ${ }^{1}$ Department of Respiratory Medicine, The First People's Hospital of Changzhou, Changzhou, Jiangsu 213000; \\ ${ }^{2}$ Department of Respiratory Medicine, The Seventh People's Hospital of Changzhou, Changzhou, Jiangsu 213011, P.R. China
}

Received August 1, 2018; Accepted February 28, 2019

DOI: $10.3892 / \mathrm{mmr} .2019 .10737$

\begin{abstract}
Research has revealed that microRNA (miR)-4500 is downregulated in non-small cell lung cancer (NSCLC), and miR-4500 suppresses tumor growth by targeting lin-28 homolog B and NRAS proto-oncogene, GTPase. In the present study, it was reported that signal transducer and activator of transcription 3 (STAT3) may function as a novel target gene for miR-4500 in NSCLC. The experiments conducted in the present study confirmed that the miR-4500 expression was decreased in NSCLC tissues and cells compared with adjacent normal tissues and a normal lung cell line. miR-4500 suppressed the cell proliferation, migration, invasion and promoted apoptosis of the human NSCLC cell lines A549 and H1975. Expression of STAT3 was negatively correlated with miR-4500 expression in vivo. A luciferase reporter assay suggested that miR-4500 directly targeted the $3^{\prime}$ untranslated region of STAT3. The tumor inhibition effect of small interfering RNA STAT3 in A549 and H1975 lines may be partially impaired by a miR-4500 inhibitor. The results of the present study suggests that miR-4500 may be a tumor suppressor and a potential therapeutic target in NSCLC.
\end{abstract}

\section{Introduction}

Lung cancer is the main reason for cancer-associated mortality, causing $>1.37$ million cases of mortality globally annually $(1,2)$. In China, the number of lung cancer cases has reached 800,000 , and 700,000 cases of mortality have been caused by lung cancer in 2017 . The 5 -year survival rate of lung cancer is as low as $\sim 18 \%$, due to the fact that the majority of

Correspondence to: Dr Jun Zhou, Department of Respiratory Medicine, The First People's Hospital of Changzhou, 185 Juqian Road, Changzhou, Jiangsu 213000, P.R. China

E-mail: zhoujunyfan@163.com

*Contributed equally

Key words: microRNA-4500, signal transducer and activator of transcription 3, proliferation, apoptosis, migration, invasion patients are in the middle or late stage when they are admitted for hospitalization and thus have lost the opportunity for surgical treatment (3). Non-small cell lung cancer (NSCLC) constitutes $85 \%$ of all lung cancer cases. The initiation and development of NSCLC is attributed to the aberrant expression of proto-oncogenes and tumor-suppressive genes, which result in tumor cell growth, metastasis and eventually tumor progression (1).

MicroRNAs (miRNAs/miRs) are short endogenous non-protein-coding RNAs that are $\sim 22$ nucleotides in length. miRNAs serve notable functions in regulating human gene expression by base pairing to the 3' untranslated region (3'UTR) of the target mRNA (4). Various miRNAs are involved in a diverse range of cellular processes, including cell proliferation, apoptosis, development and differentiation (5). Increasing evidence demonstrates that the dysregulation of miRNA expression is associated with the development and progression of various cancer types including NSCLC (6-10).

miR-4500, which is 16 nucleotides in length and is located in chromosome 13, was discovered by high-throughput sequencing technology (11). One previous study demonstrated that miR-4500 was downregulated in NSCLC lung tissues compared with their non-tumor counterparts, and that the low expression of miR-4500 promoted tumor growth by targeting lin-28 homolog B (LIN28B) and NRAS proto-oncogene, GTPase (NRAS) (12). Using a bioinformatic algorithm, signal transducer and activator of transcription proteins 3 (STAT3) was predicted to be a novel potential target of miR-4500 (13).

STAT3 has been demonstrated to be crucial in tumor development and cancer-associated inflammation (14). STAT3 may prevent apoptosis and promotes cell proliferation and angiogenesis (15). A number of miRNAs are known to interact with the 3'-UTR of STAT3 mRNA and thereby negatively regulate STAT3 (16-19). For example, miR-17, miR-20a and miR-106b control lung epithelial branching morphogenesis through the downregulation of STAT3 and mitogen-activated protein kinase 14 protein levels and followed by the regulation of E-Cadherin distribution (20). miR-9600 suppresses tumor progression and promotes paclitaxel sensitivity in NSCLC through altering STAT3 expression in NSCLC cell lines (18). 
The present study initially investigated the expression of miR-4500 and STAT3 in NSCLC tissues and the human NSCLC cell lines A549 and H1975. Then, the function of miR-4500 in cell proliferation, migration, invasion and apoptosis in vitro was examined. Furthermore, the molecular mechanism of miR-4500 in tumor progression was studied. The results of the present study suggested that miR-4500 may serve a regulatory role in NSCLC progression, and may be a novel strategy and prognostic marker for the diagnosis and prognosis of NSCLC.

\section{Materials and methods}

Human tissue samples. The present study was ethically approved by the Ethics Committee of the First People's Hospital of Changzhou (Changzhou, China). Clinical samples (NSCLC tissues and adjacent normal tissues) were collected from 40 patients with NSCLC (average age, 57; female to male ratio, 17:23; 11 patients aged $<60$ years old and 29 patients aged $\geq 60$ years old) who received surgery at The First People's Hospital of Changzhou (Changzhou, China) between July 2015 and November 2017 subsequent to obtaining written informed consent. All patient diagnoses of NSCLC were confirmed based on a pathological assay, and none of the patients received any prior cancer treatment.

Cell culture and transfection. Human NSCLC cell lines A549 and H1975 and a human normal lung cell line (16HBE), obtained from the Type Culture Collection of the Chinese Academy of Sciences (Shanghai, China), were cultured in RPMI-1640 medium (Hyclone; GE Healthcare Life Sciences, Logan, UT, USA) in the presence of $10 \%$ fetal bovine serum (FBS; Biowest, Riverside, MO, USA) and $1 \%$ penicillin/streptomycin (Gibco; Thermo Fisher Scientific, Inc., Waltham, MA, USA) in an incubator at $37^{\circ} \mathrm{C}$ in $5 \% \mathrm{CO}_{2}$. miR-4500 mimics, miRNA mimics-negative control (NC), miR-4500 inhibitor and miRNA inhibitor NC were purchased from Shanghai GenePharma Co., Ltd. (Shanghai, China). Small interfering RNA (siRNA) against human STAT3 mRNA and the control siRNA were synthesized by Guangzhou RiboBio Co., Ltd. (Guangzhou, China). Transfection was performed using Lipofectamine 2000 Reagent (Invitrogen; Thermo Fisher Scientific, Inc.), according to the manufacturer's protocol. Briefly, A549 and H1975 cells were seeded in 6-well plates at a density of $5.0 \times 10^{3}$ cells/well transfected with miRNA $(100 \mathrm{nM})$ or siRNA $(50 \mathrm{nM})$ when the cells reached $60-70 \%$ confluence. Subsequently, cells were cultured with fresh medium containing $10 \%$ FBS for $48 \mathrm{~h}$ prior to further experiments.

The target sequences of the siRNA used are as follows: siRNA-STAT3 sense, 5'-CCAGTCAGTGACCAGGCAGAA G-3' and antisense, 5'-GCACGTACTCCATCGCTGACA-3'.

RNA isolation and reverse transcription-quantitative polymerase chain reaction (RT-qPCR). Total RNA was extracted from tissues and cells using Trizol (Invitrogen; Thermo Fisher Scientific, Inc.) and reverse transcribed using a Moloney murine leukemia virus reverse transcriptase (Promega Corporation, Madison, WI, USA) at $37^{\circ} \mathrm{C}$ for $30 \mathrm{~min}$. miRNA was extracted using the miRcute miRNA Isolation
STAT3 (position 74-84) 5' ...UGACCUCGGAGUGCGCUACCUCC.

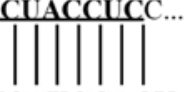

hsa-miR-4500

3' UUCUUUGAUGAUGGAGU 5

Figure 1. Predicted binding sites in the 3'-untranslated region of STAT3 mRNA and seed sequence of miR-4500. miR, microRNA; STAT3, signal transducer and activator of transcription 3.

kit (Tiangen Biotech Co., Ltd., Beijing, China). cDNA was synthesized using the One Step PrimeScript miRNA cDNA Synthesis kit according to the manufacturer's protocol (Takara Bio, Inc., Otsu, Japan). The expression levels of miR-4500 and STAT3 mRNA were determined using RT-qPCR using the SYBR ExScript RT-qPCR kit according to the manufacturer's protocol (Takara Biotech Co.,Ltd.) in the ABI 7500 Real-Time PCR system (Applied Biosystems; Thermo Fisher Scientific, Inc.) with U6 and GAPDH functioning as endogenous controls, respectively. The primers used for $\mathrm{qPCR}$ were as follows: STAT3 forward, 5'-ATCACGCCTTCTACAGACTGC-3' and reverse, 5'-CATCCTGGAGATTCTCTACCACT-3'; GAPDH forward, 5'-CCACTCCTCCACCTTTGAC-3' and reverse 5'-ACCCTGTTGCTGTAGCCA-3'; and U6 forward, 5'-CTCGCTTCGGCAGCACA-3' and reverse, 5'-AACGCT TCACGAATTTGCGT-3'. The reaction system consisting of a total of $20 \mu \mathrm{l}$ of volume was as follows: $1 \mu \mathrm{l}$ cDNA, $10 \mu \mathrm{l}$ SYBR Premix EX Taq, $1 \mu \mathrm{l}$ each of the primers $(10 \mu \mathrm{M})$ and $7 \mu \mathrm{ldd} \mathrm{dd}_{2} \mathrm{O}$. The thermocycling conditions were as follows: $95^{\circ} \mathrm{C}$ for $5 \mathrm{~min}$, followed by 40 cycles of $95^{\circ} \mathrm{C}$ for $10 \mathrm{sec}$ and $60^{\circ} \mathrm{C}$ for $30 \mathrm{sec}$. Melting curve analysis was performed at the end of each PCR cycle to confirm that only one product was amplified and detected. All fold changes were calculated using the comparative $\mathrm{Cq}\left(2^{-\Delta \Delta \mathrm{Cq}}\right)$ method using U6 or GAPDH for normalization (21).

Western blotting. Total protein was extracted from transfected cells using radioimmunoprecipitation assay buffer (Beijing Solarbio Science \& Technology Co., Ltd., Beijing, China). Protein concentration was measured with a Bicinchoninic acid Protein assay kit (Beyotime Institute of Biotechnology, Haimen, China). An equal amount of protein $(50 \mu \mathrm{g})$ per lane was separated using $10 \%$ SDS-PAGE gel and blotted onto polyvinylidene fluoride membranes. The membrane was blocked using phosphate buffered saline (PBS) with Tween-20 (0.1\% Tween in PBS) and probed with primary antibodies for STAT3 (1:1,000; cat. no. ab32124; Abcam, Cambridge, MA, USA), BCL2 apoptosis regulator (Bcl-2; 1:1,000; cat. no. ab32124; Abcam), BCL2 associated X, apoptosis regulator (Bax; 1:1,000; cat. no. ab32503; Abcam), cleaved-caspase-3 $(1: 1,000$; cat. no. ab13847; Abcam), cleaved-caspase- 9 (1:1,000; cat. no. ab13847; Abcam), matrix metalloproteinase (MMP)-2 (1:1,000; cat. no. ab37150; Abcam), MMP-9 (1:1,000; cat. no. ab73734; Abcam) and GAPDH (1:5,000; cat. no. G8795; Sigma-Aldrich; Merck KGaA, Darmstadt, Germany) at $4^{\circ} \mathrm{C}$ overnight. The membranes were then incubated with the appropriate horseradish peroxidase-conjugated anti-rabbit secondary antibody (1:5,000; cat. no. ab6858; Abcam) at room temperature for $1 \mathrm{~h}$. The membranes were visualized using an enhanced 
A

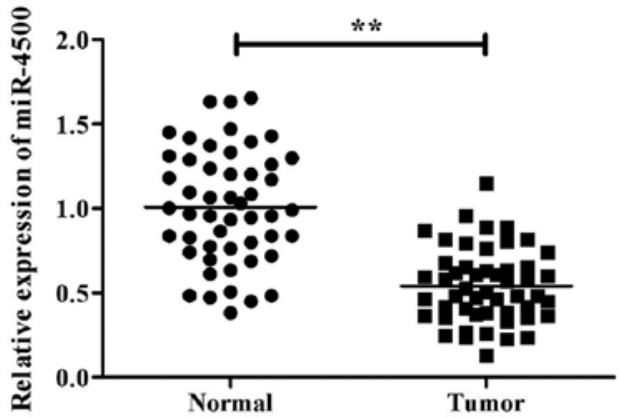

C

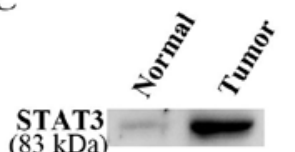
$\underset{(37 \mathrm{kDa})}{\text { GAPDH }}$

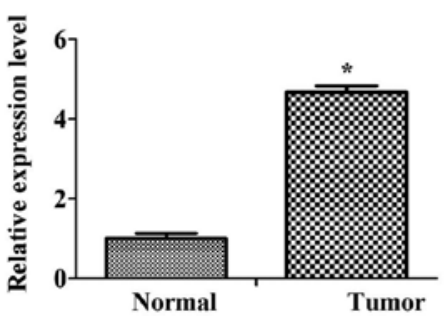

E

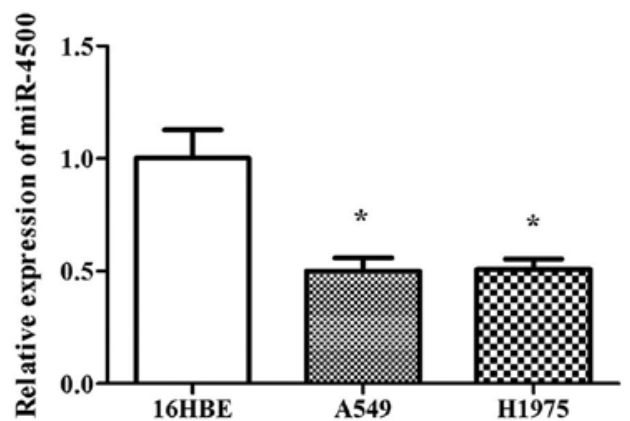

B

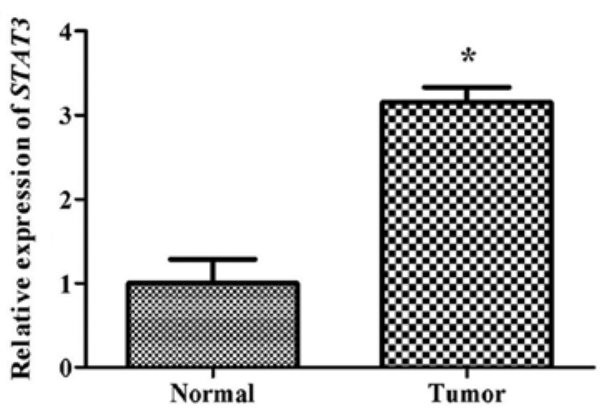

D

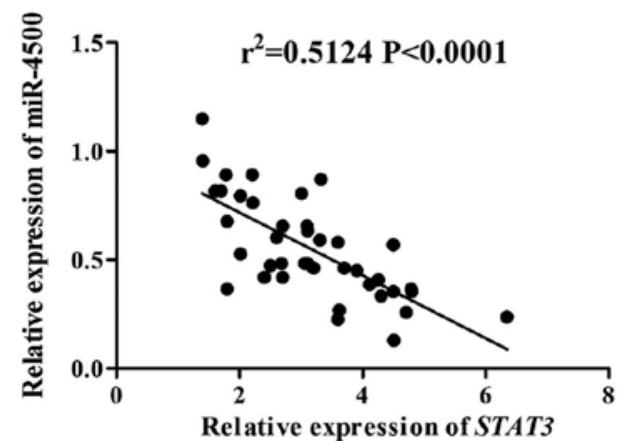

F

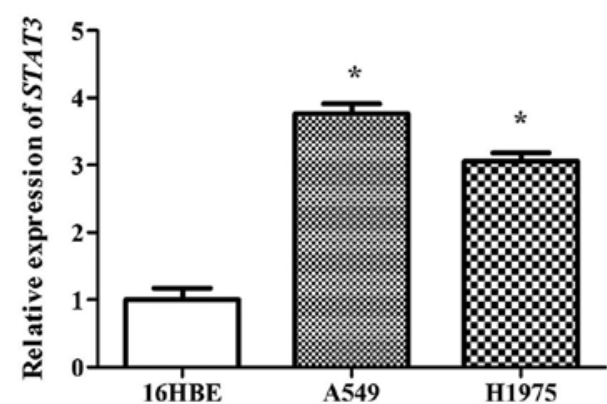

Figure 2. miR-4500 expression was downregulated and negatively correlated with STAT3 in NSCLC tissues and cell lines. RT-qPCR determined the mRNA levels of (A) miR-4500 and (B) STAT3 in NSCLC tissues and adjacent-normal lung cancer tissues. $\mathrm{n}=40$ for each group. Data were presented as the mean \pm standard deviation and each assay was performed in triplicate. ${ }^{*} \mathrm{P}<0.05$ and ${ }^{* *} \mathrm{P}<0.01$ vs. normal tissues. (C) Western blotting of STAT3 in the tumor and adjacent normal lung tissue of one patient with NSCLC. Data were presented as the mean \pm the standard deviation. $n=3$. ${ }^{*} \mathrm{P}<0.05$ vs. normal tissue. (D) Pearson's correlation analysis between miR-4500 levels and STAT3 mRNA expression levels in NSCLC tissues. n=40. RT-qPCR determined the mRNA levels of (E) miR-4500 and (F) STAT3 in A549 and H1975 cell lines and one normal lung cell line (16HBE). All data were presented as the mean \pm the standard deviation and each assay was performed in triplicate. ${ }^{*} \mathrm{P}<0.05$ vs. the $16 \mathrm{HBE}$ cell line. miR, microRNA; STAT3, signal transducer and activator of transcription 3; NSCLC, non-small cell lung cancer; RT-qPCR, reverse transcription-quantitative polymerase chain reaction.

chemiluminescent kit (Beyotime Institute of Biotechnology, Beijing, China). The immunoreactive bands were scanned using a densitometer, and the gray value of the bands were calculated automatically using Image J software version $\mathrm{k}$ 1.45 (National Institutes of Health, Bethesda, MD, USA).

Cell proliferation assay. Cell proliferation of A549 and H1975 was detected using the Cell Counting Kit-8 (CCK-8; Wuhan Boster Biological Technology, Ltd., Wuhan, China) according to the manufacturer's protocol. A colony formation assay and EdU assay were performed to confirm the CCK-8 assay results. For the EdU assay, cells were serum-starved for $24 \mathrm{~h}$, prior to treatment. EdU was added to the culture $2 \mathrm{~h}$ prior to cell collection and detected using the Click-it assay kit (Thermo Fisher Scientific, Inc.). For the colony formation assay, cells were seeded in a 6-well plate at a density of 1,000 cells/well $24 \mathrm{~h}$ after transfection. Cells were incubated for 2 weeks and the clones were fixed at room temperature for 20 min using methanol and stained with $0.1 \%$ crystal violet for $4 \mathrm{~h}$ at room temperature, and counted under a light microscope.

Cell apoptosis assay. The apoptosis of A549 and H1975 cells was detected using flow cytometry analysis. A fluorescein isothiocyanate (FITC)-Annexin V/propidium iodide (PI) Apoptosis Detection kit (BD Pharmingen; BD Biosciences, Franklin Lakes, NJ, USA) was used according to the manufacturer's protocol. All cells were collected $48 \mathrm{~h}$ post-transfection and stained using Annexin V-FITC $(5 \mathrm{ml})$ and PI $(5 \mathrm{ml})$ according to the manufacturer's protocol. Flow cytometer (Beckman Coulter, Inc., Brea, CA, USA) was used for cell apoptosis determination and analyzed using FlowJo 10.06 software (FlowJo LLC, Ashland, OR, USA). All analyses were performed in triplicate.

Wound healing assay. A549 and H1975 cells were seeded in 6 -well plates and then incubated with $10 \mu \mathrm{g} / \mathrm{ml}$ mitomycin C 
A
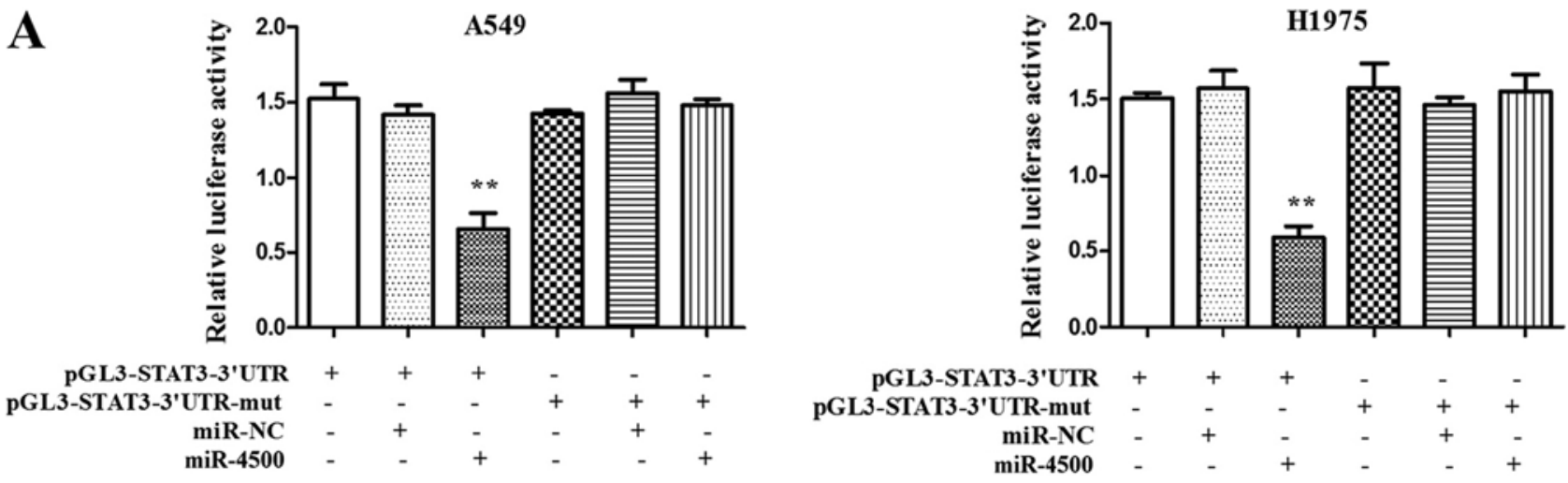

B
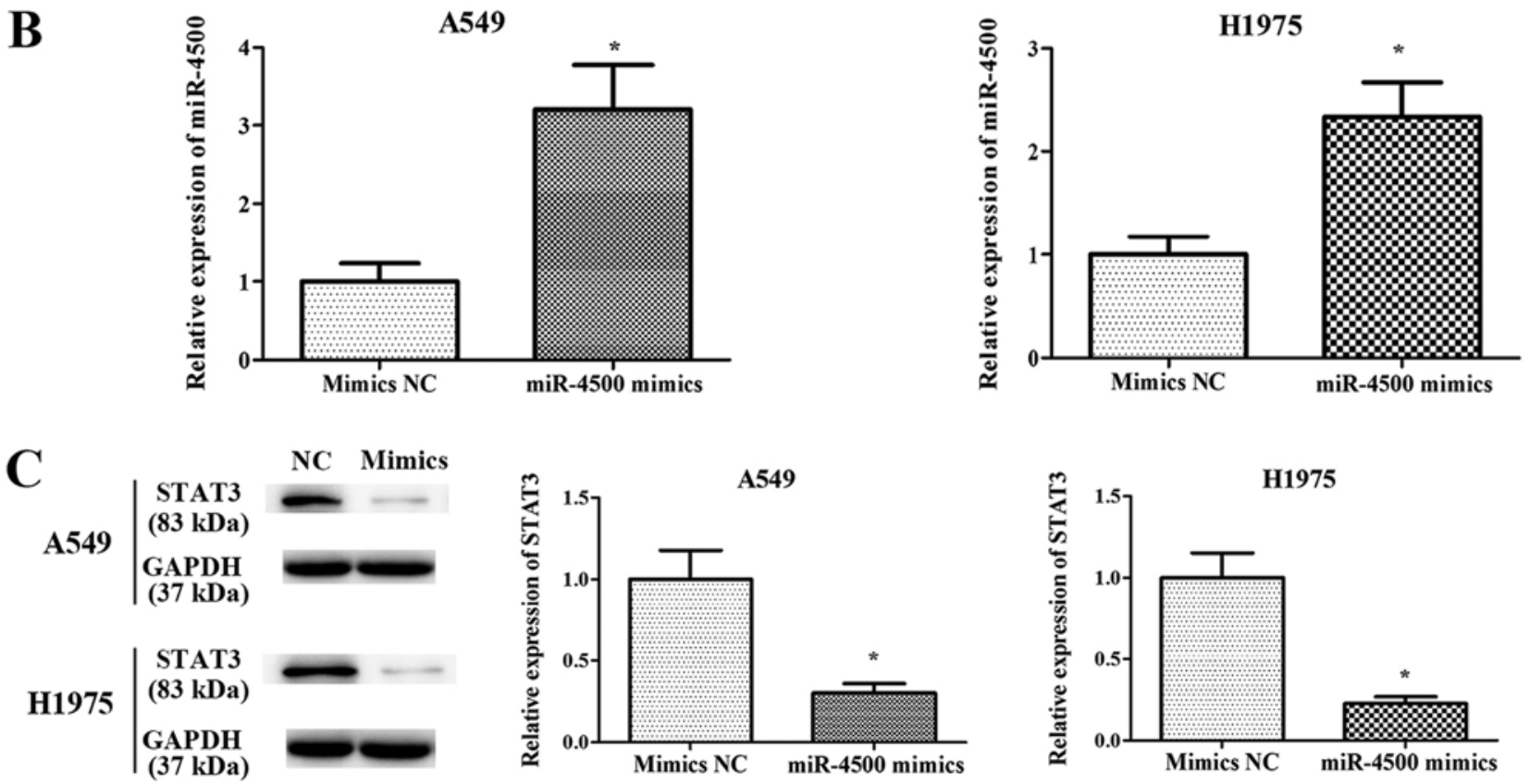

Figure 3. miR-4500 directly targets to STAT3 3'-UTR. (A) A dual luciferase reporter assay. The relative luciferase activity of the reporter plasmids containing wild-type or mutant STAT3 3'-UTR in A549 and H1975 cells co-transfected with the NC or miR-4500 mimics was detected. ${ }^{* *} \mathrm{P}<0.01 \mathrm{vs.} \mathrm{mimics} \mathrm{NC.}$ (B) Reverse transcriptase-quantitative polymerase chain reaction of miR-4500 mRNA expression levels and (C) western blotting of STAT3 protein expression levels in A549 and H1975 cell lines transfected with miR-4500 mimics and mimics NC. All data were presented as the mean \pm standard deviation and each experiment was performed in triplicate. ${ }^{*} \mathrm{P}<0.05$ vs. mimics NC. miR, microRNA; STAT3, signal transducer and activator of transcription 3; UTR, untranslated region; mut, mutant type; $\mathrm{NC}$, negative control.

for $2 \mathrm{~h}$. Wounds were created using a $200 \mu \mathrm{l}$ sterile pipette tips when the density reached $\sim 80 \%$. Photographs were obtained at $24 \mathrm{~h}$ following wound generation under a light microscope (magnification, $\mathrm{x} 200$ ).

Transwell invasion assay. A549 and H1975 cells were plated in the upper Transwell chamber (Corning Incorporated, Corning, NY, USA) that was pre-coated with Matrigel (Growth factor reduced; BD Biosciences), at a density of $4 \times 10^{4}$ cells/well in $100 \mu \mathrm{l}$ DMEM (with $0.5 \%$ FBS). The bottom chambers of the Transwell chamber were filled with DMEM with $20 \%$ FBS. After $24 \mathrm{~h}$ at $37^{\circ} \mathrm{C}$, fixed cells were washed twice with PBS and fixed with $4 \%$ paraformaldehyde for $30 \mathrm{~min}$ at room temperature. Subsequently, cells were stained with $0.1 \%$ crystal violet for $30 \mathrm{~min}$ at room temperature. The migration and invasion cells were counted and imaged under a light microscope (magnification, $\mathrm{x} 200$ ).
Luciferase reporter assay. The primers used for pGL3-STAT3-3'UTR construction were as follows: Sense, 5'-GGTACCGTGGCCTGCCAGTTGCAGA-3' and antisense, 5'-AAGCTTCTCAGTCGTATCTTTCTG-3'. PCR products were cloned into the pGL3-basic vector using KpnI/HindIII sites. The mutant version of this construct (pGL3-STAT3-mut-3'UTR) carrying 4 base pair substitutions in the miR-4500 target sites was obtained by site-directed mutagenesis using the QuikChange Site-Directed Mutagenesis kit (Agilent Technologies, Inc., Santa Clara, CA, USA) according to the manufacturer's protocol. The A549 and H1975 cells were seeded at a concentration of $5.0 \times 10^{3}$ cells/well onto 24 -well plates and co-transfected with either miR-4500 mimics or miR-NC and pGL3-STAT3-3'UTR or pGL3-STAT3-mut-3'UTR using Lipofectamine 2000 (Invitrogen; Thermo Fisher Scientific, Inc.) for $36 \mathrm{~h}$ at $37^{\circ} \mathrm{C}$. After $36 \mathrm{~h}$, luciferase activity was measured using the Dual-Glo Luciferase Assay System 


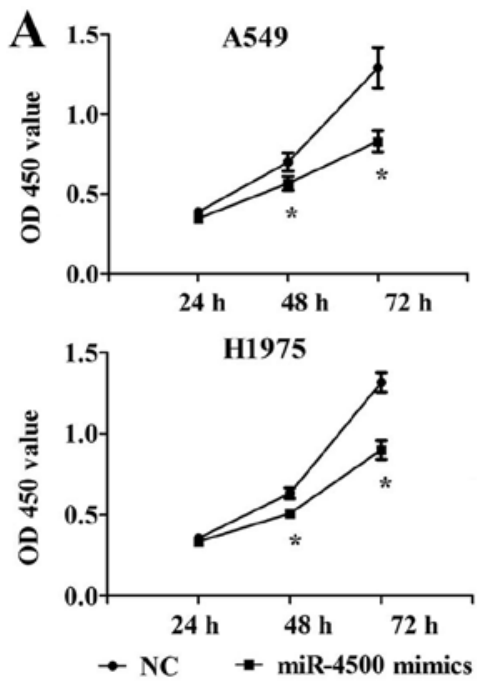

C
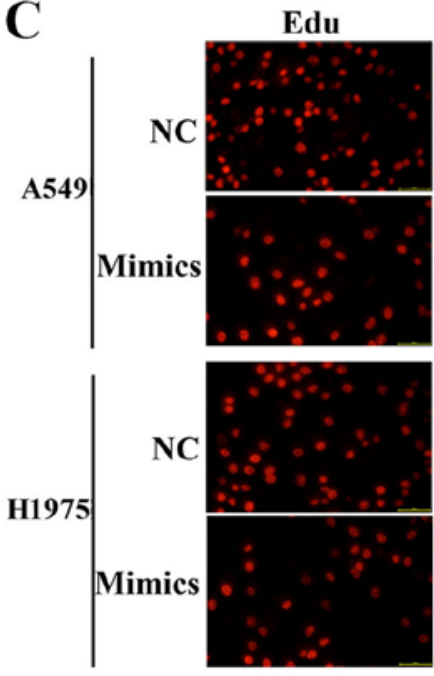

B

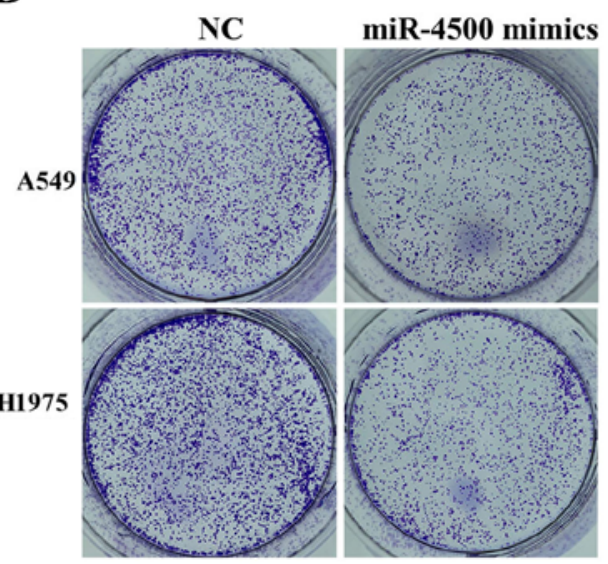

A549
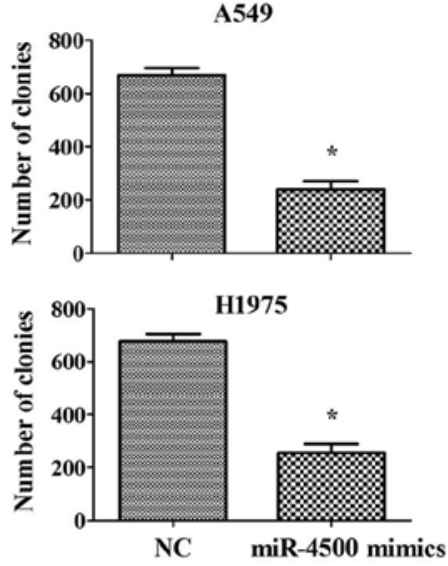

A549
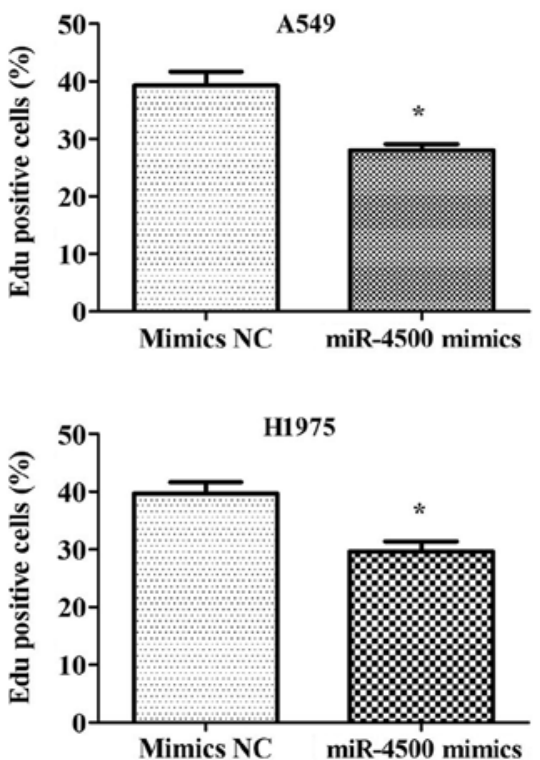

Figure 4. miR-4500 suppresses NSCLC cell proliferation in vitro. (A) A Cell Counting Kit-8 assay, (B) a colony formation assay and (C) a EdU assay of A549 and H1975 cells following transfected with miR-4500 mimics or mimics NC. Magnification, x200. All data were presented as the mean \pm standard deviation and each experiment was performed in triplicate. "P<0.05 vs. the NC group. miR, microRNA; NC, negative control; OD, optical density.

(Promega Corporation). Renilla luciferase was used to normalize the luciferase activity.

Statistical analysis. All results are reported as the mean \pm standard deviation and at least three independent replicates were performed. GraphPad software 5.0 (GraphPad Software, Inc., La Jolla, CA, USA) was used to perform the statistical analysis. Pearson's correlation analysis was used to assess the correlation between STAT3 mRNA expression and miR-4500 levels. Differences between two groups were calculated using a Student's t-test. Differences between multiple groups were analyzed using a one-way analysis of variance with Tukey's post hoc test. $\mathrm{P}<0.05$ was considered to indicate a statistically significant difference.

\section{Results}

STAT3 is a putative target of miR-4500 in NSCLC. Bioinformatics algorithms [TargetScan software (http://www. targetscan.org/)] (22) implied that there was putative miR-4500 target site in the 3'-UTR of STAT3 (Fig. 1). Considering that STAT3 may be one of the key oncogenic drivers in NSCLC, the present study further investigated the association between miR-4500 and STAT3.

miR-4500 expression is negatively correlated with STAT3 in NSCLC tissues and cell lines. miR-4500 and STAT3 expression level were studied in 40 human NSCLC lung tissues. RT-qPCR results indicated that the expression levels of miR-4500 in NSCLC lung tissues were significantly lower compared with normal tissues $(\mathrm{P}<0.01$; Fig. $2 \mathrm{~A})$. Conversely, STAT3 was significantly upregulated in NSCLC lung tissues on the mRNA and protein levels compared with normal tissues $(\mathrm{P}<0.05$; Fig. 2B and $\mathrm{C})$. Additionally, Pearson's correlation analysis was used to assess the correlation between STAT3 mRNA expression and miR-4500 levels in NSCLC lung tissues, and the results indicated that the expression levels of STAT3 mRNA and miR-4500 were significantly negatively correlated $\left(r^{2}=0.5124, \mathrm{P}<0.0001\right.$; Fig. 2D). Furthermore, NSCLC cell lines (A549 and H1975) also exhibited significantly lower 

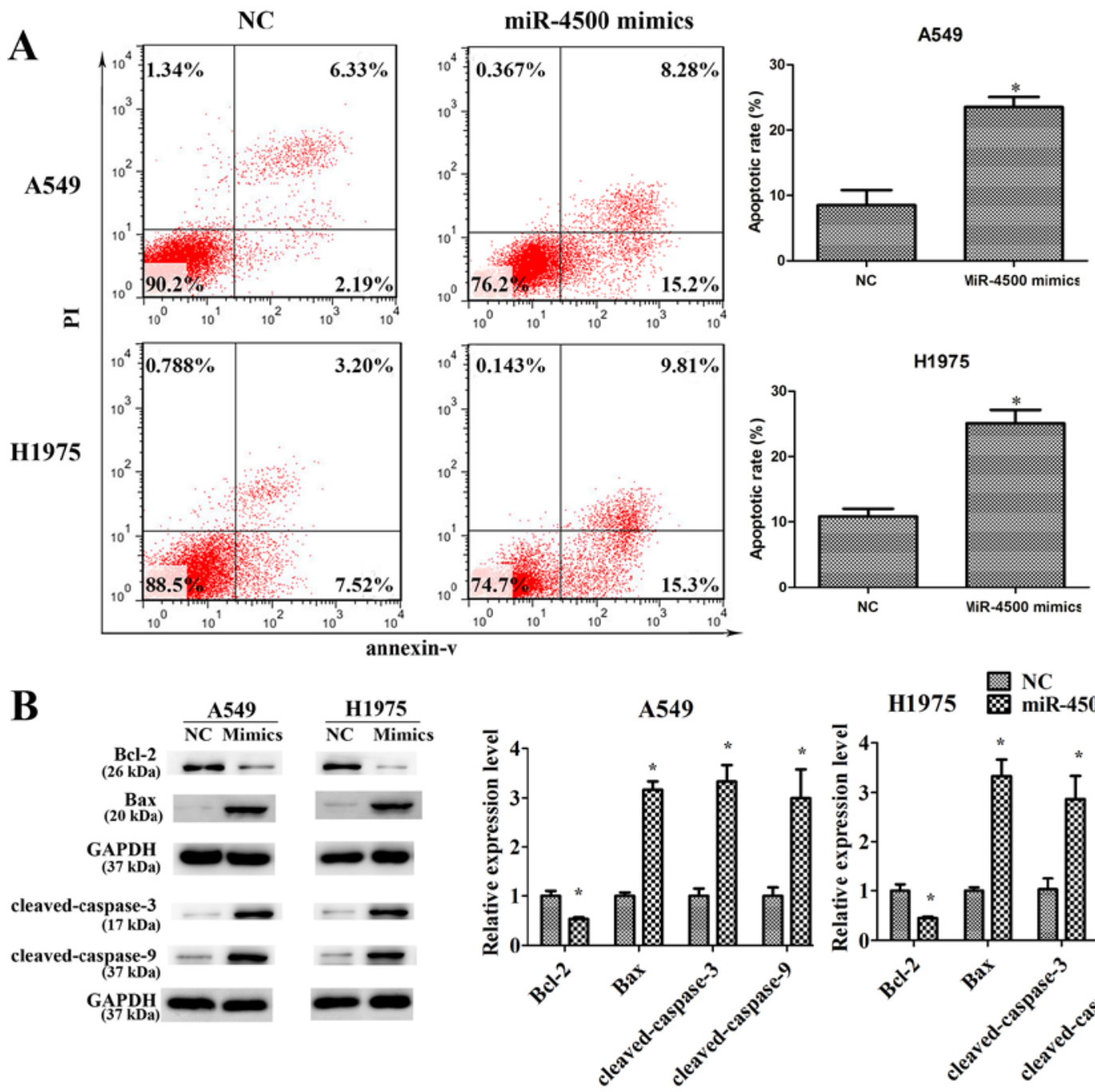

Figure 5. miR-4500 induces apoptosis in vitro. (A) Apoptosis was determined using flow cytometry analysis of A549 and H1975 cells following transfection with miR-4500 mimics or mimics NC. (B) Western blotting determined the protein expression levels of Bcl-2, Bax, cleaved-caspase- 3 and cleaved-caspase- 9 in A549 and H1975 cell lines transfected with miR-4500 mimics or the NC. All data were presented as the mean \pm standard deviation and each experiment was performed in triplicate. "P $<0.05$ vs. the NC group. miR, microRNA; NC, negative control; PI, propidium iodide; Bcl-2, BCL2 apoptosis regulator; Bax, BCL2 associated X, apoptosis regulator.

miR-4500 expression levels and higher STAT3 expression levels compared with a normal lung cell line, $16 \mathrm{HBE}(\mathrm{P}<0.05$; Fig. 2E and F).

miR-4500 directly targets STAT3 in NSCLC. To validate the interaction between STAT3 and miR-4500, luciferase reporter assays were performed. The results indicated that the overexpression of miR-4500 significantly decreased the luciferase activity of wild type STAT3-3'-UTR compared with mutated STAT3-3'-UTR $(\mathrm{P}<0.01)$, indicating that miR-4500 targeted the 3 '-UTR of STAT3 directly in NSCLC (Fig. 3A).

miR-4500 suppresses NSCLC cell proliferation and invasion and induces apoptosis in vitro. In order to investigate the function of miR-4500 in cell proliferation and apoptosis, miR-4500 was overexpressed in A549 and H1975 cells by transfecting the cells with miR-4500 mimics. RT-qPCR results (Fig. 3B) indicated that a 2-4 fold significant increase in miR-4500 mRNA levels were expressed subsequent to transfection with mimics compared with the negative control $(\mathrm{P}<0.05)$. STAT3 expression was significantly decreased in A549 and H1975 cells following transfection with miR-4500 mimics $(\mathrm{P}<0.05$; Fig. 3C). A CCK-8 assay indicated that miR-4500 mimics inhibited cell proliferation significantly when compared with the negative control at the 48 and $72 \mathrm{~h}$ mark $(\mathrm{P}<0.05$; Fig. 4A). The same conclusion was derived from the colony formation assay $(\mathrm{P}<0.05$; Fig. $4 \mathrm{~B})$ and the EdU assay $(\mathrm{P}<0.05$; Fig. 4C). Furthermore, miR-4500 mimics significantly promoted cell apoptosis in A549 and H1975 cells compared with the negative control $(\mathrm{P}<0.05)$, with the anti-apoptotic protein Bcl2 significantly downregulated and pro-apoptosis proteins (Bax, cleaved-caspase-3 and cleaved-caspase-9) significantly upregulated compared with the negative control $(\mathrm{P}<0.05$; Fig. 5).

A previous study has demonstrated the function of miR-4500 in NSCLC cell proliferation and apoptosis, with no data on cell migration and invasion (12). Therefore, a wound healing assay and a Transwell assay were performed in order to study the function of miR-4500 in NSCLC cell migration 


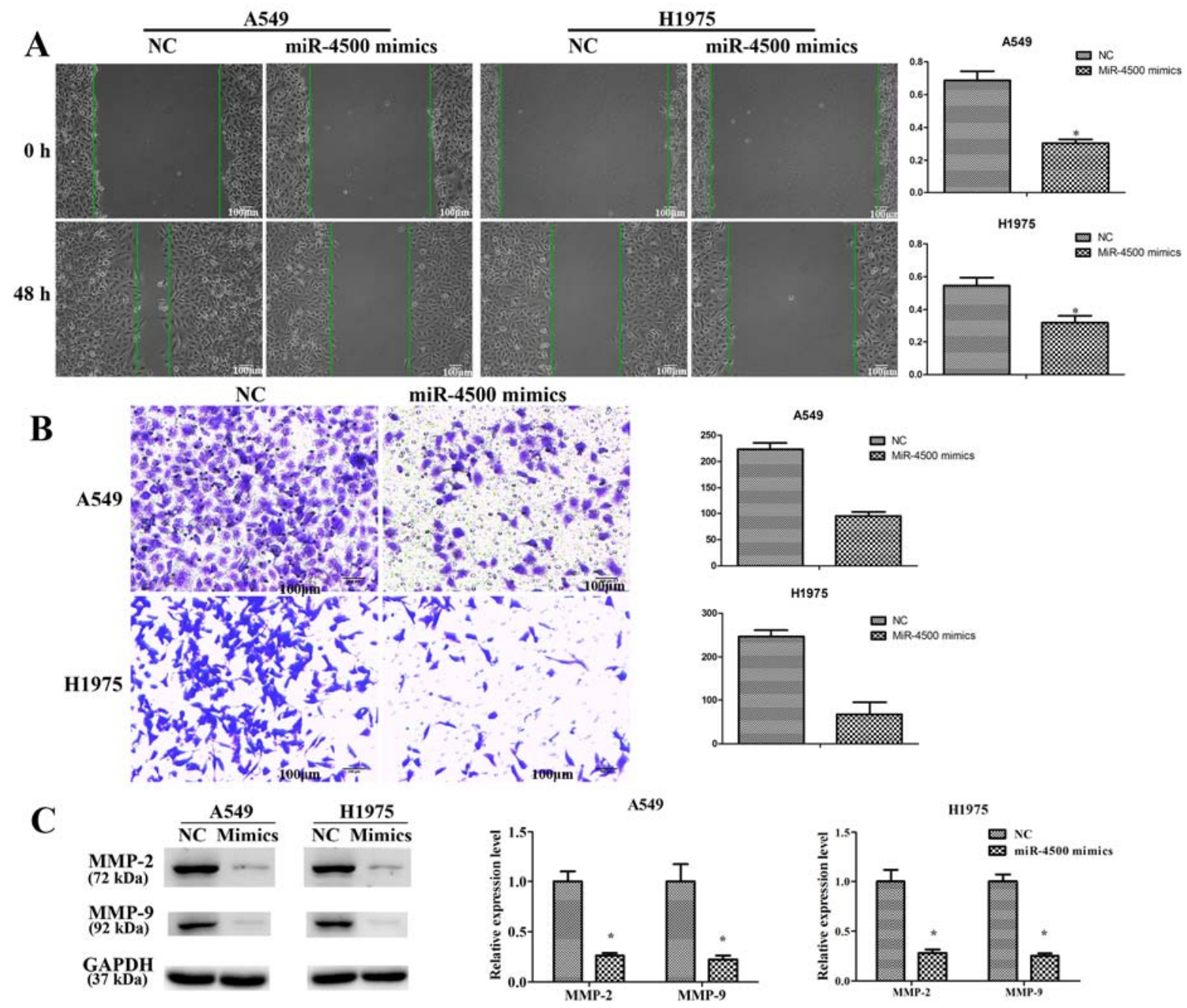

Figure 6. miR-4500 suppresses NSCLC cell migration and invasion in vitro. (A) A wound healing assay and (B) a Transwell invasion assay of A549 and H1975 cells subsequent to transfection with miR-4500 mimics or the NC. (C) Western blotting determined the protein expression levels of MMP-2 and MMP-9 in A549 and H1975 cells following transfection with miR-4500 mimics or the NC. All data were presented as the mean \pm standard deviation and each experiment was performed in triplicate. ${ }^{*} \mathrm{P}<0.05$ vs. the $\mathrm{NC}$ group. $\mathrm{NC}$, negative control; miR, microRNA; MMP, matrix metalloproteinase.

and invasion. The results revealed a significant positive effect of miR-4500 in migration and invasion inhibition compared with the NC group $(\mathrm{P}<0.05$; Fig. 6A and $\mathrm{B})$. MMPs participate in cancer cell invasion by degrading the extracellular matrix $(23,24)$. Western blotting revealed that the protein expression levels of MMP-2 and MMP-9 were significantly inhibited in A549 and H1975 cells subsequent to transfection with miR-4500 mimics compared with the NC group $(\mathrm{P}<0.05$; Fig. 6C).

miR-4500 suppresses NSCLC cell proliferation, migration and invasion and induces apoptosis partially by downregulating STAT3 in vitro. To identify the function of STAT3 in miR-4500-suppressed NSCLC cell progression, STAT3 expression was successfully significantly knocked down in A549 and H1975 cells by transfection with STAT3-targeted siRNA ( $\mathrm{P}<0.05$; Fig. 7A). It was revealed that STAT3 downregulation significantly suppressed cell proliferation $(\mathrm{P}<0.05)$, migration $(\mathrm{P}<0.05)$ and invasion $(\mathrm{P}<0.05)$ and significantly induced apoptosis $(\mathrm{P}<0.05)$ compared with the control. However, miR-4500 inhibitors partially restored the effects of si-STAT3 on cell growth and migration in A549 and H1975 cells $(\mathrm{P}<0.05$; Figs. 7B-D and 8). This data implies that miR-4500 suppresses NSCLC cell proliferation, migration and invasion and induces apoptosis partially by downregulating STAT3 in vitro.

\section{Discussion}

miRNAs control various processes, including cellular growth, proliferation, differentiation, regulation of the cell cycle, aging, apoptosis, metabolism and neuronal patterning. An increasing number of miRNAs have been demonstrated to be associated with the development and progression of different types of cancer (25-29). All this indicates the potential function of miRNAs as novel diagnostic or prognostic biomarkers.

The let-7 family is one of the earliest identified miRNA families, originally determined to serve a function in the timing of larval development in Caenorhabditis elegans (30). The members of let-7 are highly expressed in normal lung tissues and have been identified to negatively control multiple different oncogenes (31). miRNA-4500 is one of the let-7 family members, and has been reported to be downregulated in NSCLC, consequently promoting tumor growth by targeting LIN28B and NRAS (32). 
A

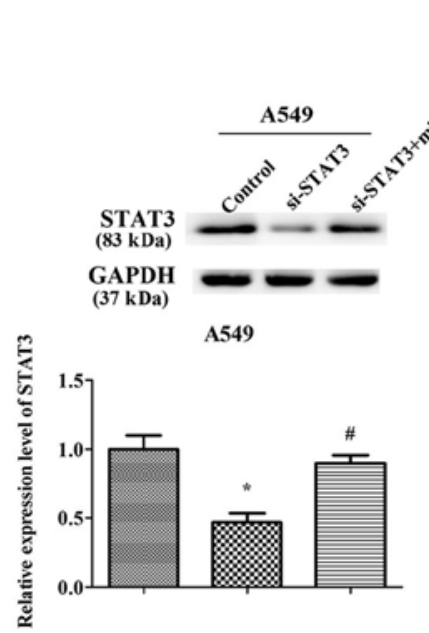

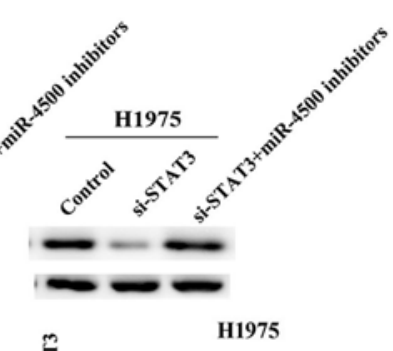

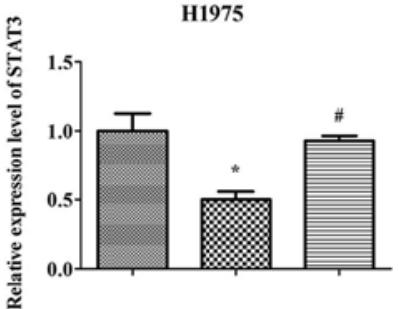

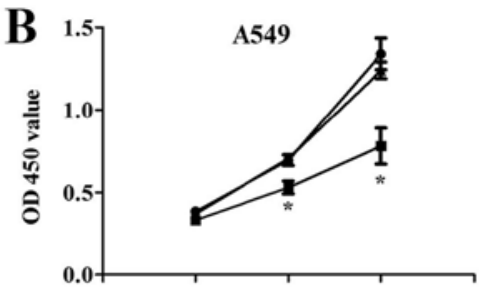

H1975

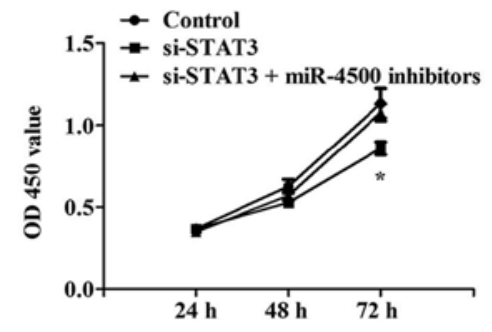

C

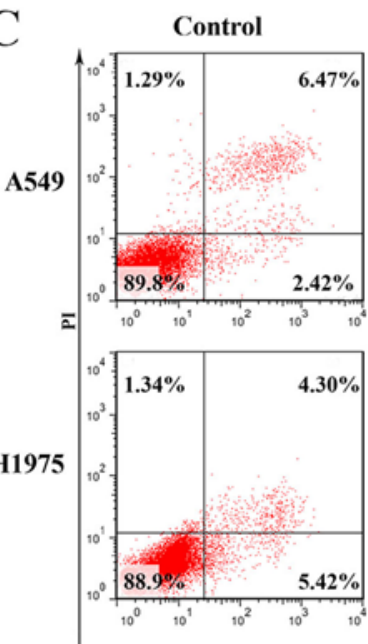

si-STAT3 si-STAT3+miR-4500 inhibitor
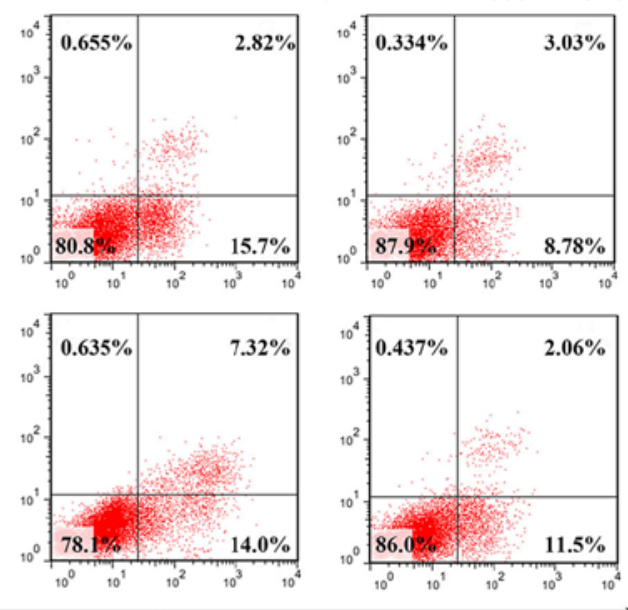

Annexin V

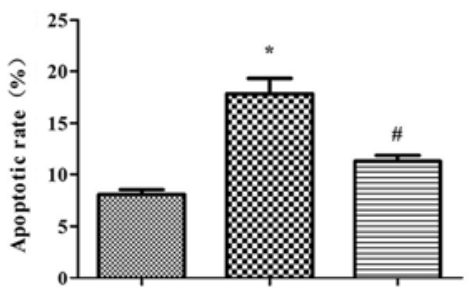

H1975

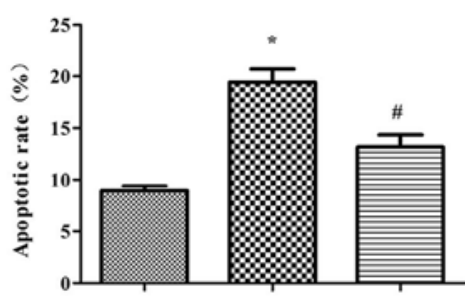

D
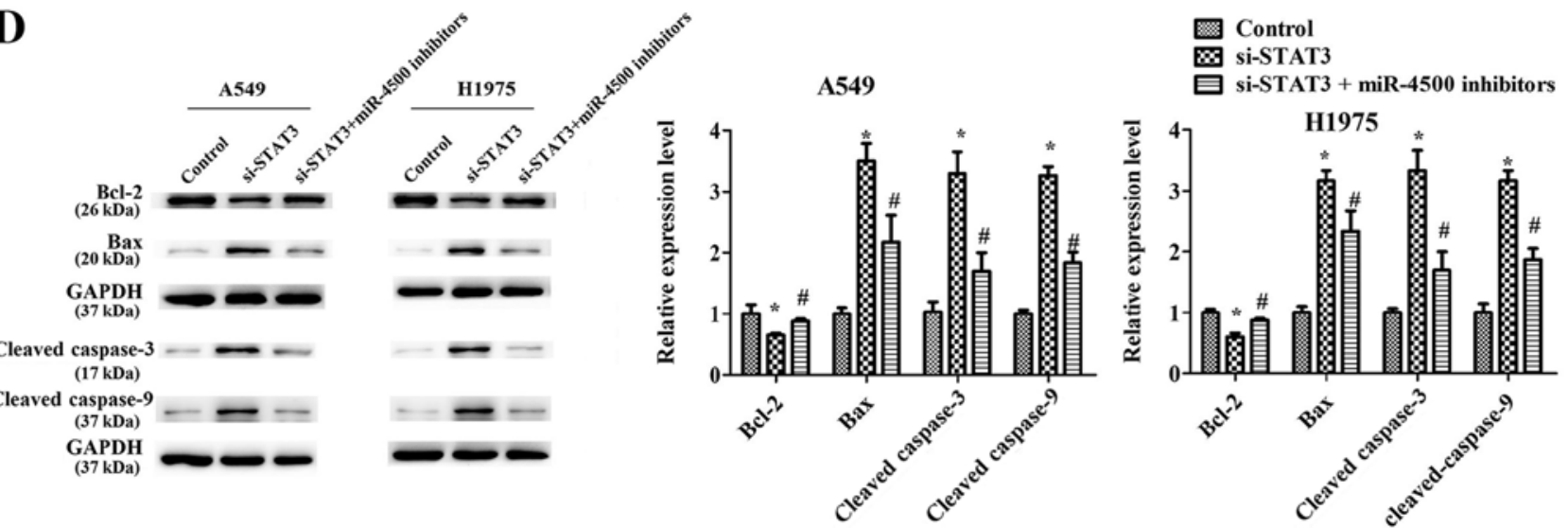

Figure 7. miR-4500 suppresses non-small cell lung cancer cell proliferation and induces apoptosis partially by downregulating STAT3 in vitro. (A) Western blotting determined the protein expression levels of STAT3 in A549 and H1975 cells following transfection with si-STAT3 or NC or a combination of si-STAT3 and miR-4500 inhibitors. (B) Cell Counting Kit-8 assays and (C) an apoptosis flow cytometry assay of A549 and H1975 cells following transfection with si-STAT3 or NC or a combination of si-STAT3 and miR-4500 inhibitors. (D) Western blotting determined the protein expression levels of Bax, Bcl-2, cleaved-caspase-3 and cleaved-caspase-9 protein in A549 and H1975 cell lines transfected with si-STAT3 or NC or a combination of si-STAT3 and miR-4500 inhibitors. All data were presented as the mean \pm standard deviation and each experiment was performed in triplicate. ${ }^{*} \mathrm{P}<0.05$ vs. the control. ${ }^{\#} \mathrm{P}<0.05 \mathrm{vs}$. the si-STAT3 group. miR, microRNA; STAT3, signal transducer and activator of transcription 3; si-, small interfering RNA; OD, optical density; Bcl-2, BCL2 apoptosis regulator; Bax, BCL2 associated X, apoptosis regulator; NC, negative control; PI, propidium iodide.

The present study confirmed the lower expression of miR-4500 in NSCLC tissues and cells compared with normal control tissues and cells. Cell lines A549 and H1975 were selected to study the role of miR-4500 in tumorigenesis.
Results indicate that miR-4500 suppressed cell proliferation, migration, invasion and promoted apoptosis in vitro.

STAT3 is a well-known oncogenic gene in NSCLC (33-35). The constitutive activation of STAT3 is a common feature in 


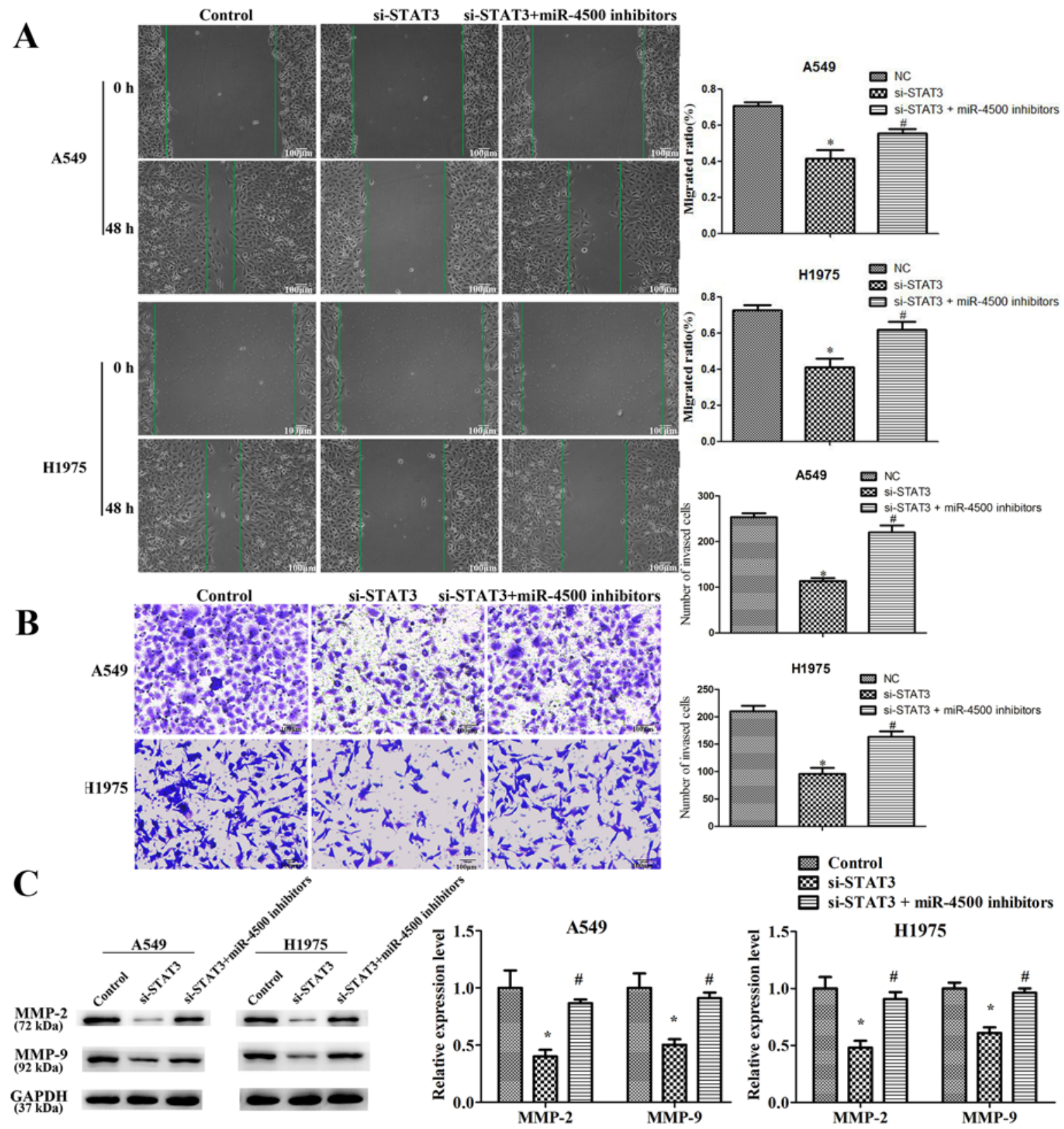

Figure 8. miR-4500 suppresses non-small cell lung cancer cell migration and invasion by downregulating STAT3 in vitro. (A) A Wound healing assay and (B) a Transwell invasion assay of A549 and H1975 cells subsequent to transfection with si-STAT3 or NC or a combination of si-STAT3 and miR-4500 inhibitors. (C) Western blotting determined the protein expression levels of MMP-2 and MMP-9 in A549 and H1975 cells transfected with with si-STAT3 or NC or a combination of si-STAT3 and miR-4500 inhibitors. All data were presented as the mean \pm standard deviation and each was performed in triplicate. ${ }^{*} \mathrm{P}<0.05$ vs. the control group. ${ }^{*} \mathrm{P}<0.05$ vs. the si-STAT3 group. miR, microRNA; STAT3, signal transducer and activator of transcription 3; si-, small interfering RNA; MMP, matrix metalloproteinase.

NSCLC, and has also been proposed to serve a notable function in tumor resistance to conventional and targeted small-molecule therapies (36-38). STAT3 suppresses cancer cell apoptosis via the inactivation of either extrinsic or intrinsic apoptotic pathways $(39,40)$. Meanwhile, STAT3 promotes NSCLC cell proliferation and angiogenesis $(12,13)$.

Bioinformatic algorithms (TargetScan) implied that there was a putative miR-4500 target site in the 3'-UTR of STAT3. The present study revealed that the expression of STAT3 is negatively correlated with miR-4500 expression in the tissues of 40 patients with NSCLC. Furthermore, targeting miR-4500 and STAT3 was confirmed using a luciferase reporter assay.
Additionally, the tumor inhibition effect of si-STAT3 in A549 and H1975 lines may be partially restored using a miR-4500 inhibitor, which suggests that miR-4500 may suppress tumor progression in NSCLC by regulating STAT3. In order to confirm this, further studies will also be performed in the future in cells overexpressing STAT3 and miR-4500.

Altogether, miR-4500, that was demonstrated to be significantly downregulated in NSCLC tissues and cell lines, may suppress NSCLC cell proliferation, migration and invasion, and promote apoptosis by regulating STAT3 expression, indicating that miR-4500 may be a tumor suppressor and a potential therapeutic target in NSCLC. 


\section{Acknowledgements}

Not applicable.

\section{Funding}

No funding was received.

\section{Availability of data and material}

The datasets used during the present study are available from the corresponding author on reasonable request.

\section{Authors' contributions}

$\mathrm{ZL}$ and $\mathrm{ZZ}$ were major contributors in sample collection, performing the experiments, data interpretation and preparing the paper. $\mathrm{HB}, \mathrm{QZ}, \mathrm{SZ}, \mathrm{LZ}$ and $\mathrm{XZ}$ participated in sample collection, performing the experiments and data interpretation. JZ produced the experimental design and revised the manuscript. All authors read and approved the final manuscript.

\section{Ethics approval and consent to participate}

Written informed consent was obtained from each patient and the present study was ethically approved by the Ethics Committee of the First People's Hospital of Changzhou (Changzhou, China).

\section{Patient consent for publication}

Not applicable.

\section{Competing interests}

The authors declare that they have no competing interests.

\section{References}

1. Inamura K: Lung Cancer: Understanding its molecular pathology and the 2015 WHO classification. Front Oncol 7: 193, 2017.

2. McIntyre A and Ganti AK: Lung cancer-A global perspective. J Surg Oncol 115: 550-554, 2017.

3. Siegel RL, Miller KD and Jemal A: Cancer statistics, 2016. CA Cancer J Clin 66: 7-30, 2016.

4. Deng S, Calin GA, Croce CM, Coukos G and Zhang L: Mechanisms of microRNA deregulation in human cancer. Cell Cycle 7: 2643-2646, 2008.

5. Bartel DP: MicroRNAs: Genomics, biogenesis, mechanism, and function. Cell 116: 281-297, 2004.

6. Calin GA and Croce CM: MicroRNA signatures in human cancers. Nat Rev Cancer 6: 857-866, 2006.

7. Fang C, Chen YX, Wu NY, Yin JY, Li XP, Huang HS, Zhang W, Zhou HH and Liu ZQ: MiR-488 inhibits proliferation and cisplatin sensibility in non-small-cell lung cancer (NSCLC) cells by activating the eIF3a-mediated NER signaling pathway. Sci Rep 7: 40384, 2017.

8. Li T, Ding ZL, Zheng YL and Wang W: MiR-484 promotes non-small-cell lung cancer (NSCLC) progression through inhibiting Apaf-1 associated with the suppression of apoptosis. Biomed Pharmacother 96: 153-164, 2017.

9. Lin L, Tu HB, Wu L, Liu M and Jiang GN: MicroRNA-21 regulates non-small cell lung cancer cell invasion and chemo-sensitivity through SMAD7. Cell Physiol Biochem 38: 2152-2162, 2016.

10. Yin J, Wang M, Jin C and Qi Q: miR-101 sensitizes A549 NSCLC cell line to CDDP by activating caspase 3-dependent apoptosis. Oncol Lett 7: 461-465, 2014.
11. Jima DD, Zhang J, Jacobs C, Richards KL, Dunphy $\mathrm{CH}$, Choi WW, Au WY, Srivastava G, Czader MB, Rizzieri DA, et al: Deep sequencing of the small RNA transcriptome of normal and malignant human $\mathrm{B}$ cells identifies hundreds of novel microRNAs. Blood 116: e118-e127, 2010.

12. Zhang L, Qian J, Qiang Y, Huang H, Wang C, Li D and $\mathrm{Xu}$ B: Down-regulation of miR-4500 promoted non-small cell lung cancer growth. Cell Physiol Biochem 34: 1166-1174, 2014.

13. Lin Q, Zheng H, Xu J, Zhang F and Pan H: LncRNA SNHG16 aggravates tumorigenesis and development of hepatocellular carcinoma by sponging miR-4500 and targeting STAT3. J Cell Biochem: Feb 18, 2019 (Epub ahead of print) Doi: 10.1002/jcb.28440.

14. Yu H, Pardoll D and Jove R: STATs in cancer inflammation and immunity: A leading role for STAT3. Nat Rev Cancer 9: 798-809, 2009.

15. Harada D, Takigawa N and Kiura K: The role of STAT3 in non-small cell lung cancer. Cancers (Basel) 6: 708-722, 2014.

16. Liu J, Fei D, Xing J and Du J: MicroRNA-29a inhibits proliferation and induces apoptosis in rheumatoid arthritis fibroblast-like synoviocytes by repressing STAT3. Biomed Pharmacother 96: 173-181, 2017.

17. Shan D, Shang Y and Hu T: MicroRNA-411 inhibits cervical cancer progression by directly targeting STAT3. Oncol Res 27: 349-358, 2019.

18. Sun CC, Li SJ, Zhang F, Zhang YD, Zuo ZY, Xi YY, Wang L and Li DJ: The novel miR-9600 suppresses tumor progression and promotes paclitaxel sensitivity in non-small-cell lung cancer through altering STAT3 expression. Mol Ther Nucleic Acids 5: e387, 2016

19. Haghikia A, Hoch M, Stapel B and Hilfiker-Kleiner D: STAT3 regulation of and by microRNAs in development and disease. JAKSTAT 1: 143-150, 2012.

20. Carraro G, El-Hashash A, Guidolin D, Tiozzo C, Turcatel G, Young BM, De Langhe SP, Bellusci S, Shi W, Parnigotto PP and Warburton D: miR-17 family of microRNAs controls FGF10-mediated embryonic lung epithelial branching morphogenesis through MAPK14 and STAT3 regulation of E-Cadherin distribution. Dev Biol 333: 238-250, 2009.

21. Wan LY, Woo CS, Turner PC, Wan JM and El-Nezami H: Individual and combined effects of Fusarium toxins on the mRNA expression of pro-inflammatory cytokines in swine jejunal epithelial cells. Toxicol Lett 220: 238-246, 2013.

22. Koller D and Friedman N: Probabilistic Graphical Models: Principles and techniques-adaptive computation and machine learning. Probabilistic graphical models-principles and techniques, 2009.

23. Du WW, Ling F, Li M, Yang X, Liang Y, Peng C, Qian W, O'Malley YQ, Askeland RW, Sugg SL, et al: MicroRNA miR-24 enhances tumor invasion and metastasis by targeting PTPN9 and PTPRF to promote EGF signaling. J Cell Sci 126: 1440-1453, 2013.

24. Li S, Li Z, Guo F, Qin X, Liu B, Lei Z, Song Z, Sun L, Zhang HT, You $J$ and Zhou Q: miR-223 regulates migration and invasion by targeting Artemin in human esophageal carcinoma. J Biomed Sci 18: 24, 2011.

25. Hong L, Han Y, Zhang H, Zhao Q and Qiao Y: miR-210: A therapeutic target in cancer. Expert Opin Ther Targets 17: 21-28, 2013.

26. Xia B, Li H, Yang S, Liu T and Lou G: MiR-381 inhibits epithelial ovarian cancer malignancy via YY1 suppression. Tumour Biol 37: 9157-9167, 2016.

27. Wang C, Chen Q, Li S, Li S, Zhao Z, Gao H, Wang X, Li B, Zhang W, Yuan Y, et al: Dual inhibition of PCDH9 expression by miR-215-5p up-regulation in gliomas. Oncotarget 8 : 10287-10297, 2017.

28. Danza K, De Summa S, Pinto R, Pilato B, Palumbo O, Merla G, Simone G and Tommasi S: MiR-578 and miR-573 as potential players in BRCA-related breast cancer angiogenesis. Oncotarget 6: 471-483, 2015 .

29. $\mathrm{Xu} \mathrm{HY,} \mathrm{Wang} \mathrm{Y}$, Zhang $\mathrm{H}$ and $\mathrm{Xu} \mathrm{J}$ : The long non-coding RNA UCA1, as a prognostic biomarker for high grade serous ovarian carcinoma. Eur J Gynaecol Oncol 38: 883-889, 2017.

30. Reinhart BJ, Slack FJ, Basson M, Pasquinelli AE, Bettinger JC, Rougvie AE, Horvitz HR and Ruvkun G: The 21-nucleotide let-7 RNA regulates developmental timing in Caenorhabditis elegans. Nature 403: 901-906, 2000 
31. Johnson CD, Esquela-Kerscher A, Stefani G, Byrom M, Kelnar K, Ovcharenko D, Wilson M, Wang X, Shelton J, Shingara J, et al: The let-7 microRNA represses cell proliferation pathways in human cells. Cancer Res 67: 7713-7722, 2007.

32. Yu FY, Tu Y, Deng Y, Guo C, Ning J, Zhu Y, Lv X and Ye H: MiR-4500 is epigenetically downregulated in colorectal cancer and functions as a novel tumor suppressor by regulating HMGA2. Cancer Biol Ther 17: 1149-1157, 2016.

33. Song L, Turkson J, Karras JG, Jove R and Haura EB: Activation of Stat 3 by receptor tyrosine kinases and cytokines regulates survival in human non-small cell carcinoma cells. Oncogene 22: 4150-4165, 2003.

34. Alvarez JV, Greulich H, Sellers WR, Meyerson M and Frank DA: Signal transducer and activator of transcription 3 is required for the oncogenic effects of non-small-cell lung cancer-associated mutations of the epidermal growth factor receptor. Cancer Res 66: 3162-3168, 2006.

35. Looyenga BD, Hutchings D, Cherni I, Kingsley C, Weiss GJ and Mackeigan JP: STAT3 is activated by JAK2 independent of key oncogenic driver mutations in non-small cell lung carcinoma PLoS One 7: e30820, 2012.

36. Gao SP, Mark KG, Leslie K, Pao W, Motoi N, Gerald WL, Travis WD, Bornmann W, Veach D, Clarkson B, et al: Mutations in the EGFR kinase domain mediate STAT3 activation via IL-6 production in human lung adenocarcinomas. J Clin Invest 117 3846-3856, 2007.
37. Yin Z, Zhang Y, Li Y, Lv T, Liu J and Wang X: Prognostic significance of STAT3 expression and its correlation with chemoresistance of non-small cell lung cancer cells. Acta Histochem 114: 151-158, 2012.

38. You S, Li R, Park D, Xie M, Sica GL, Cao Y, Xiao ZQ and Deng X: Disruption of STAT3 by niclosamide reverses radioresistance of human lung cancer. Mol Cancer Ther 13: 606-616, 2014.

39. Epling-Burnette PK, Liu JH, Catlett-Falcone R, Turkson J, Oshiro M, Kothapalli R, Li Y, Wang JM, Yang-Yen HF, Karras J, et al: Inhibition of STAT3 signaling leads to apoptosis of leukemic large granular lymphocytes and decreased Mcl-1 expression. J Clin Invest 107: 351-362, 2001.

40. Ivanov VN, Bhoumik A, Krasilnikov M, Raz R, OwenSchaub LB, Levy D, Horvath CM and Ronai Z: Cooperation between STAT3 and c-jun suppresses Fas transcription. Mol Cell 7: 517-528, 2001.

(i) (9) This work is licensed under a Creative Commons Attribution-NonCommercial-NoDerivatives 4.0 International (CC BY-NC-ND 4.0) License. 